\title{
No differences in subjective knee function between surgical techniques of anterior cruciate ligament reconstruction at 2-year follow-up: a cohort study from the Swedish National Knee Ligament Register
}

\author{
Eric Hamrin Senorski ${ }^{1} \cdot$ David Sundemo $^{2}$. Christopher D. Murawski ${ }^{3}$. \\ Eduard Alentorn-Geli ${ }^{4,5,6,7} \cdot$ Volker Musahl $^{3} \cdot$ Freddie Fu $^{3} \cdot$ Neel Desai $^{2,8}$. \\ Anders Stålman ${ }^{9}$ Kristian Samuelsson ${ }^{2,8}$
}

Received: 25 January 2017 / Accepted: 9 March 2017 / Published online: 17 March 2017

(C) The Author(s) 2017. This article is an open access publication

\begin{abstract}
Purpose The purpose of this study was to investigate how different techniques of single-bundle anterior cruciate ligament (ACL) reconstruction affect subjective knee function via the Knee injury and Osteoarthritis Outcome Score (KOOS) evaluation 2 years after surgery. It was hypothesized that the surgical techniques of single-bundle ACL reconstruction would result in equivalent results with respect to subjective knee function 2 years after surgery.

Methods This cohort study was based on data from the Swedish National Knee Ligament Register during the 10-year period of 1 January 2005 through 31 December 2014. Patients who underwent primary single-bundle ACL reconstruction with hamstrings tendon autograft were included. Details on surgical technique were collected using a web-based questionnaire comprised of essential AARSC items, including utilization of accessory medial portal drilling, anatomic tunnel placement, and visualization of insertion sites and landmarks. A repeated measures
\end{abstract}

Electronic supplementary material The online version of this article (doi:10.1007/s00167-017-4521-y) contains supplementary material, which is available to authorized users.

Kristian Samuelsson

kristian@samuelsson.cc

1 Department of Health and Rehabilitation, Institute of Neuroscience and Physiology, The Sahlgrenska Academy, University of Gothenburg, Göteborg, Sweden

2 Department of Orthopaedics, Institute of Clinical Sciences, The Sahlgrenska Academy, University of Gothenburg, Göteborg, Sweden

3 Department of Orthoapedic Surgery, University of Pittsburgh School of Medicine, Pittsburgh, PA, USA

4 Fundación García-Cugat, Barcelona, Spain
ANOVA and an additional linear mixed model analysis were used to investigate the effect of surgical technique on the $\mathrm{KOOS}_{4}$ from the pre-operative period to 2-year follow-up.

Results A total of 13,636 patients who had undergone single-bundle ACL reconstruction comprised the study group for this analysis. A repeated measures ANOVA determined that mean subjective knee function differed between the pre-operative time period and at 2-year followup $(p<0.001)$. No differences were found with respect to the interaction between $\mathrm{KOOS}_{4}$ and surgical technique or gender. Additionally, the linear mixed model adjusted for age at reconstruction, gender, and concomitant injuries showed no difference between surgical techniques in $\mathrm{KOOS}_{4}$ improvement from baseline to 2-year follow-up. However, $\mathrm{KOOS}_{4}$ improved significantly in patients for all surgical techniques of single-bundle ACL reconstruction $(p<0.001)$; the largest improvement was seen between the pre-operative time period and at 1-year follow-up.

Conclusion Surgical techniques of primary single-bundle ACL reconstruction did not demonstrate differences in the improvement in baseline subjective knee function as

Artroscopia GC, SL, Barcelona, Spain

6 Mutualidad Catalana de Futbolistas - Delegación Cataluña, Federación Española de Fútbol, Barcelona, Spain

7 Department of Orthopaedic Surgery, Mayo Clinic, Rochester, MN, USA

8 Department of Orthopaedics, Sahlgrenska University Hospital, Mölndal, Sweden

9 Department of Molecular Medicine and Surgery, Stockholm Sports Trauma Research Center, Karolinska Institutet, Stockholm, Sweden 
measured with the $\mathrm{KOOS}_{4}$ during the first 2 years after surgery. However, subjective knee function improved from pre-operative baseline to 2-year follow-up independently of surgical technique.

Keywords Register - Anterior cruciate ligament $\cdot A C L$. KOOS · Anatomic $\cdot$ Checklist $\cdot$ Patient-reported outcome

\section{Introduction}

Optimizing long-term outcomes after anterior cruciate ligament (ACL) injury remains a challenge for both physicians and physical therapists. Although good results are reported across the literature, numerous studies highlight suboptimal results and areas of improvement, including knee function [22, 25], return to sport [4, 14], as well as quality of life and development of osteoarthritis [9, 11]. Patientreported outcome measures (PROMs) should be utilized to highlight the patient's perspective on treatment outcome and represent the cornerstone in evaluating the success of intervention [24, 32]. In the case of ACL reconstruction, the Knee injury and Osteoarthritis Outcome Score (KOOS) evaluates subjective knee function and is one of the most frequently reported in the literature [13,31].

The goals of ACL reconstruction are to restore the anatomy as closely as possible to the native knee, reestablish both biological and biomechanical functions, and prevent the development and/or progression of osteoarthritis. Over the last several decades, the surgical techniques for single-bundle ACL reconstruction have evolved and the traditional transtibial drilling technique has recently come under scrutiny. In this regard, it has been shown that transtibial drilling has the tendency to result in a non-anatomic reconstruction when evaluated in reference to the native ACL footprints [20, 34]. In comparison, anatomic reconstruction techniques, predominantly involving transportal tunnel drilling, have demonstrated superior results in both biomechanical and clinical studies when compared to nonanatomic techniques [18, 36]. However, several studies have suggested that grafts placed anatomically are exposed to greater (i.e. native) in situ forces as opposed to those placed non-anatomically [3, 23, 35]. In this regard, a study from the Danish Knee Ligament Reconstruction Register reported an increased risk of revision ACL surgery when a transportal technique was compared to reconstructions performed using a transtibial technique [28]. There are conflicting results in treatment outcome with regard to surgical factors in previous studies. However, most studies only investigate single surgical factors in a limited cohort.

Recently, the anatomic anterior cruciate ligament reconstruction scoring checklist (AARSC) was published as a tool to evaluate anatomic ACL reconstruction. This tool provides the opportunity to study how detailed knowledge regarding the surgical procedure of ACL reconstruction can affect treatment outcome. For instance, anatomic ACL surgery, characterized by the presence of essential AARSC items, was associated with a lower risk of revision surgery compared with anatomic bone tunnel placement via transportal drilling [7]. However, the potential association between AARSC and PROMs has not yet been studied and it therefore remains unknown as to how recovery in subjective knee function is affected by the surgical techniques of single-bundle ACL reconstruction.

The aim of this study was to investigate how different surgical techniques of single-bundle ACL reconstruction affect subjective knee function during the first 2 years after ACL reconstruction. The secondary aim was to compare subjective knee function stratified by surgical technique of single-bundle reconstruction pre-operatively, and at 1 and 2 years of follow-up. It was hypothesized that the surgical techniques of single-bundle ACL reconstruction would result in equivalent results with respect to subjective knee function 2 years after surgery.

\section{Materials and methods}

\section{Participants}

On 25 November 2015, patient data were extracted from the Swedish National Knee Ligament Register (SNKLR). Inclusion was set to patients aged 13-49 years who underwent primary single-bundle ACL reconstruction with hamstrings tendon (HT) autograft in the 10-year period ranging from 1 January 2005 to 31 December 2014. The follow-up time period was initiated at the date of primary ACL reconstruction and ended at the 2-year follow-up. Patients who underwent revision ACL surgery before the 2-year followup period were excluded. Patients were also excluded if information on the exact date for the index or revision ACL reconstruction, or details of the surgeon who performed the procedure were missing. The inclusion and exclusion criteria are summarized in Table 1.

\section{The Swedish National Knee Ligament Register}

The SNKLR is a nationwide database that collects prospective data on ACL injuries and associated knee surgery. The registry utilizes a web-based protocol consisting of two parts: one surgeon-reported section and one patientreported section. The surgeon-reported section includes information regarding the patients' activity at the time of injury, time from injury to reconstruction, graft selection, fixation techniques, and previous surgery. The surgeon registers all surgical procedures on the injured knee, including 
Table 1 Summary of inclusion and exclusion criteria

Inclusion criteria
Primary ACL reconstruction
ACL reconstruction using hamstring tendon autograft
Single-bundle ACL reconstruction
Age $13-49$ years
Year of surgery $2005-2013$
Exclusion criteria
Concomitant ligament injury requiring repair/reconstruction
Concomitant fracture/tendon injury
Concomitant vascular injury
Early contralateral ACL or revision surgery, within 550 days of
index surgery

$A C L$ anterior cruciate ligament, KOOS Knee injury and Osteoarthritis Outcome Score

concomitant injuries and treatment of the menisci and/ or cartilage. The patient-reported section includes two PROMs:

- Knee injury and Osteoarthritis Outcome Score [31], for subjective functional knee-related outcome. The KOOS has high test-retest reliability for patients with knee injuries. The ICC has been described as $0.85-0.93$ for the sub-scale of pain, $0.83-0.95$ for the sub-scale of symptoms, $0.75-0.91$ for the sub-scale of function in daily activities, $0.61-0.89$ for the sub-scale of function in sport and recreation, and $0.83-0.95$ for the sub-scale knee-related QoL [2]. The minimal important change in KOOS is considered to be $8-10$ points for all sub-scales [19].

- European Quality of Life-Five Dimension [26], for health-related quality of life.

The SNKLR has reported a coverage (proportion of participating units in relation to all eligible units) of $92.9 \%$ and completeness (proportion of target population in the registry) $>90 \%$, with a $50-70 \%$ response rate for the patient-reported outcome measures [10]. Additionally, a non-response analysis has been performed, showing that the register is valid despite the sub-optimal number of patients responding at follow-up [29].

\section{Surgical techniques of single-bundle ACL reconstruction}

To evaluate surgical technique, a web-based questionnaire was created to collect detailed information from ACL surgeons in Sweden. The questionnaire included items from the AARSC. The AARSC has been tested for validity and reliability, and consists of 17 items covering surgical technique and 1 item relating to documentation of bone tunnel placement. The checklist allows for calculation of an 'anatomic score' with a total of 19 points [6].

Each item in the questionnaire contains a two-part specified response: first, surgeons were asked whether they 'Always' or 'Never' used the surgical technique; second, surgeons were asked whether they still performed the surgical technique today. A time interval of identified surgical techniques was created for each surgeon who responded. For the study, it was necessary to identify the corresponding patients from the register that the specific surgeon had operated on, in addition to determining the surgical technique used for that specific patient. Therefore, the questionnaire was not answered anonymously by surgeons.

A total of 108 surgeons $(61.7 \%)$ replied to the questionnaire [7]. From the results of the questionnaire, groups were created with specific combinations of surgical techniques of single-bundle ACL reconstruction based on eight relevant items selected from the questionnaire. Each group had a mandatory 'Yes' or 'No' answer requirement for certain items that subsequently identified that particular group (Table 2).

\section{Outcome}

Primary outcomes consisted of all sub-scales of the $\mathrm{KOOS}_{4}$. The KOOS is a knee-specific score, containing five sub-scales evaluating both the short- and long-term consequences of knee injuries, which includes post-traumatic osteoarthritis [31]. The $\mathrm{KOOS}_{4}$ is an average score of four KOOS sub-scales, in which function throughout daily living is excluded to avoid any ceiling effect due to the fact that relatively young and active patients rarely have difficulties with function in daily living [12].

\section{Statistical analysis}

Tables were generated using Microsoft Word (Version 14.0.7, Microsoft Corp., Redmond, Washington, USA). A statistician assigned to the SNKLR performed all statistical analyses, which was undertaken using a standard statistical software package (SPSS Version 23.0, IBM Corp, Armonk, New York, USA). Data were characterized according to the level of measurement as nominal scale data, ordinal scale data, and ratio scale data. Means of normally distributed continuous data were compared with the independent-samples $t$ test. Univariate ANOVA adjusted for age at index ACL reconstruction and gender was used to analyse the interaction of surgical technique and dimensions of the KOOS. Pairwise comparisons with $t$ test were used to study differences between surgical techniques at pre-operative and 1- and 2-year follow-up (Supplementary file). All available patients with complete data at a single follow-up were included in the cross-sectional analyses. A 


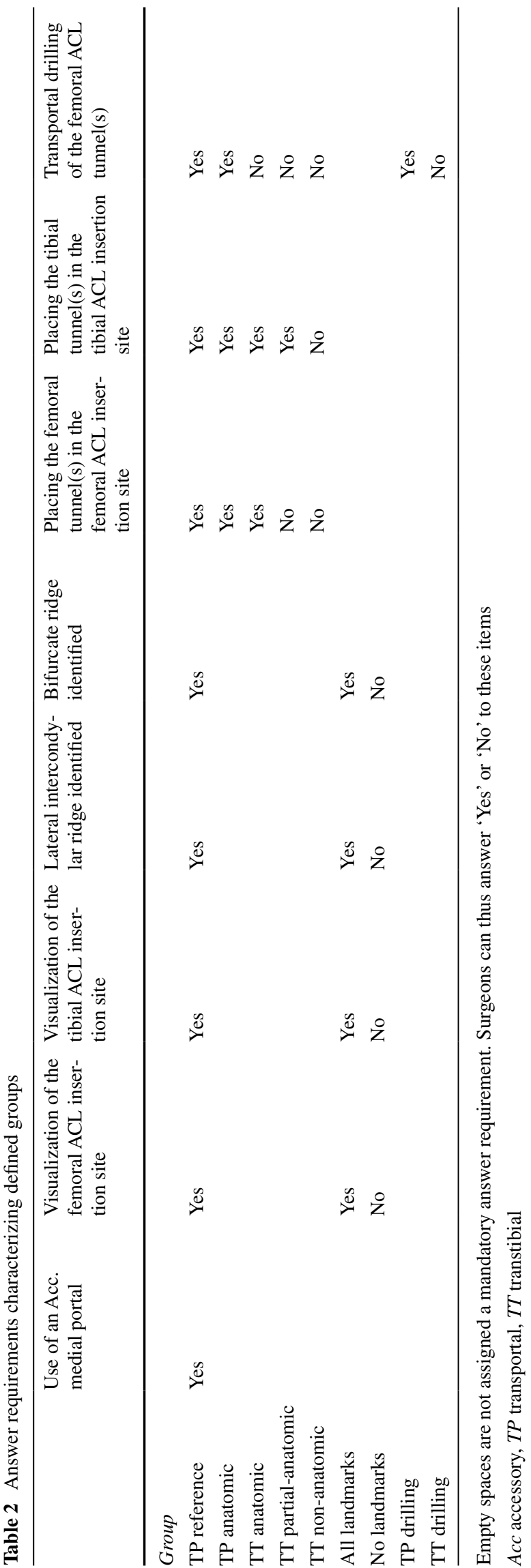

general linear model was created by a mixed ANOVA with repeated measures to analysis the change in $\mathrm{KOOS}_{4}$ and the interaction with age at index ACL reconstruction, gender, and surgical techniques. Only patients with complete data from all three follow-ups were included in the repeated measures analysis. Mauchly's test of sphericity was used to test the assumption of sphericity. If violated a GreenhouseGeisser correction was used. Alpha was set to $p<0.05$. An additional pairwise repeated measures analysis was conducted with a linear mixed model with fixed effects of age at index reconstruction, gender, and concomitant injuries, to account the occasional loss of $\mathrm{KOOS}_{4}$ data among patients at any point of follow-up.

\section{Results}

Data from 30,388 unique patients identified in the SNKLR between January 2005 and December 2014. Of these patients, a total of 20,913 were eligible for inclusion, and after applying all the exclusion criteria, data from 13,636 patients were included in the study (Fig. 1). Demographics of the included patients with complete data for the analyses are presented in Table 3.

\section{Repeated measures analysis}

A total of 2843 patients (1520 women and 1323 men) who had undergone single-bundle ACL reconstruction were included in the repeated measure analysis of $\mathrm{KOOS}_{4}$ from the pre-operative time point to follow-up at 2 years. Mauchly's test of sphericity indicated that the assumption of sphericity had been violated, $\chi^{2}(2)=338.678$, ( $p<0.001)$, and therefore, a Greenhouse-Geisser correction was used. A repeated measures ANOVA determined that no differences were found for the interaction between subjective knee function, $\mathrm{KOOS}_{4}$, and surgical techniques (Fig. 2). However, $\mathrm{KOOS}_{4}$ interaction with surgical technique significantly increased from pre-operatively to follow-up at 2 years $(p=0.006)$. Post hoc analysis of within group change revealed that $\mathrm{KOOS}_{4}$ significantly increased from pre-operatively to 1 -year follow-up and pre-operative to 2-year follow-up for all surgical techniques of singlebundle ACL reconstruction $(p<0.001)$. However, no difference was found between 1 - and 2-year follow-up (Table 4).

\section{Linear mixed model analysis}

The linear mixed model analysis accounted for the occasional loss of $\mathrm{KOOS}_{4}$ data among patients. In total, 12,133 unique patients were included in the analysis. No differences were found for the interaction of $\mathrm{KOOS}_{4}$ and surgical 


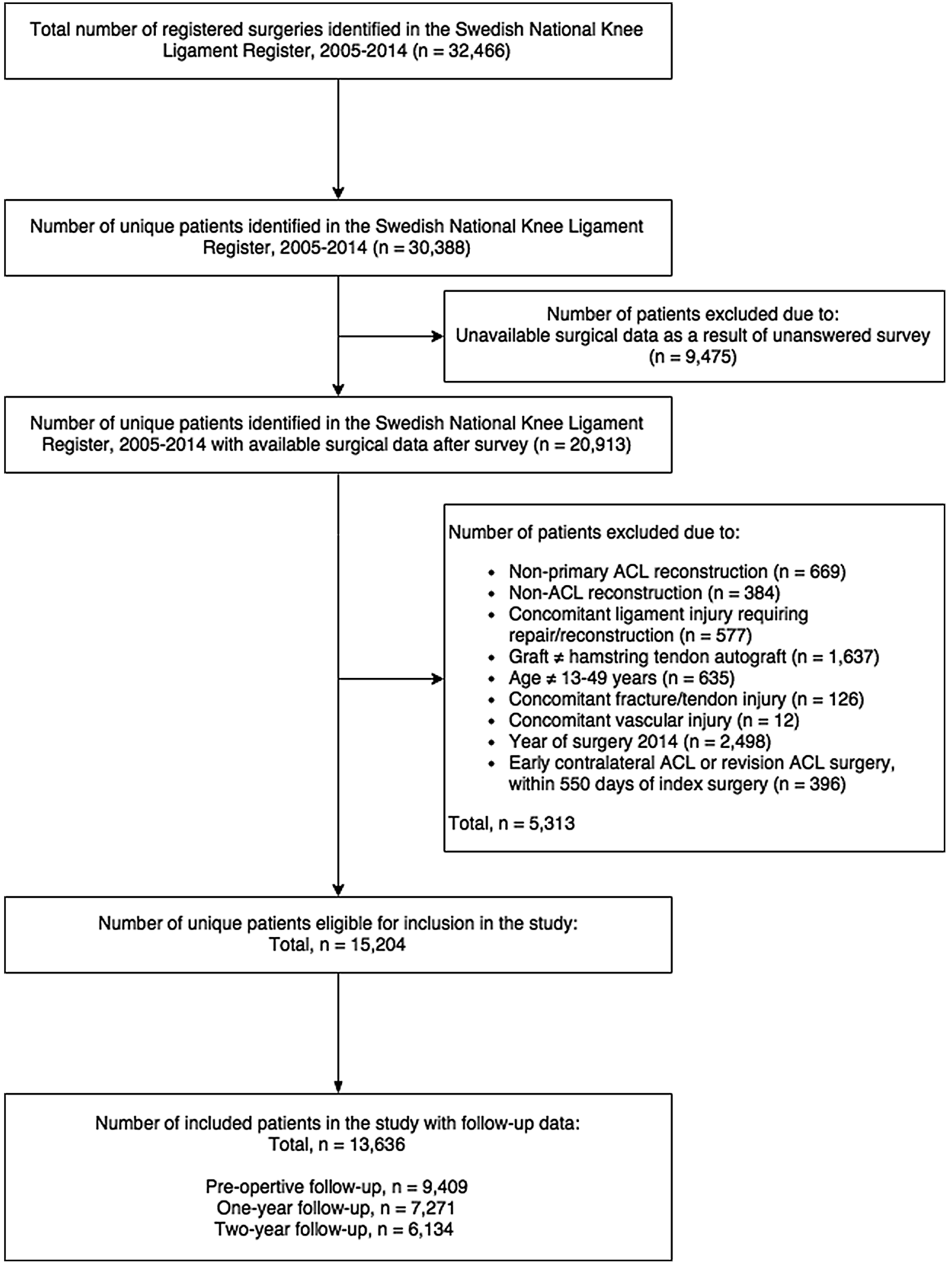

Fig. 1 Flow chart demonstrating the selection of eligible patients from the Swedish National Knee Ligament Register

techniques of single-bundle ACL reconstruction with fixed adjustments for confounding factors, which included age at reconstruction, gender, and concomitant injuries (Table 5).
Post hoc analysis of within group change revealed that $\mathrm{KOOS}_{4}$ significantly increased from pre-operatively to 1 -year follow-up and pre-operative to 2-year follow-up for 
Table 3 Patient characteristics at index anterior cruciate ligament reconstruction

\begin{tabular}{|c|c|c|c|c|c|c|}
\hline \multirow[t]{2}{*}{ Descriptive } & \multicolumn{6}{|l|}{$\begin{array}{l}\text { Surgical technique } \\
n(\%)\end{array}$} \\
\hline & $\begin{array}{l}\text { TP reference } \\
n=5287(34.8)\end{array}$ & $\begin{array}{l}\text { TT non-anatomic } \\
n=1271(8.4)\end{array}$ & $\begin{array}{l}\text { TT anatomic } \\
n=1978(13.0)\end{array}$ & $\begin{array}{l}\text { TT partial-anatomic } \\
n=1492(9.8)\end{array}$ & $\begin{array}{l}\text { TP anatomic } \\
n=3608(23.7)\end{array}$ & $\begin{array}{l}\text { Total cohort } \\
n=13,636(100)\end{array}$ \\
\hline \multicolumn{7}{|l|}{ Gender } \\
\hline Female & $2265(42.8)$ & $555(43.7)$ & $888(44.9)$ & $639(42.8)$ & $1579(43.8)$ & $5926(43.5)$ \\
\hline \multicolumn{7}{|c|}{ Age at index ACL reconstruction } \\
\hline $13-15$ & $449(8.5)$ & $88(6.9)$ & $169(8.5)$ & $86(5.8)$ & $194(5.4)$ & $986(7.2)$ \\
\hline $16-20$ & $1480(28.0)$ & $401(31.5)$ & $586(28.7)$ & $392(26.3)$ & $1068(29.6)$ & 3909 (28.7) \\
\hline $21-25$ & $1092(20.7)$ & $282(22.2)$ & $334(16.9)$ & $315(21.1)$ & $786(21.8)$ & 2809 (20.6) \\
\hline $26-30$ & $799(15.1)$ & $162(12.7)$ & $260(13.1)$ & $232(15.5)$ & $515(14.2)$ & $1968(14.4)$ \\
\hline $31-35$ & $506(9.6)$ & $127(10.0)$ & $240(12.1)$ & $164(11.0)$ & $358(9.9)$ & $1395(10.2)$ \\
\hline $36-40$ & $462(8.7)$ & $107(8.4)$ & $198(10.0)$ & $169(11.3)$ & $303(8.4)$ & $1239(9.2)$ \\
\hline $40-49$ & $499(9.4)$ & $104(8.2)$ & 209 (10.6) & $134(9.0)$ & $384(10.6)$ & $1330(9.8)$ \\
\hline Mean age (years) & 25.3 & 26.3 & 26.5 & 26.3 & 26.0 & \\
\hline \multicolumn{7}{|c|}{ Concomitant injury (yes) } \\
\hline Meniscus & $2462(46.6)$ & 478 (37.6) & $734(37.1)$ & $578(38.7)$ & $1615(44.8)$ & $5867(43.0)$ \\
\hline Cartilage & $1454(27.5)$ & $411(32.2)$ & $491(24.8)$ & $346(23.3)$ & $823(22.8)$ & $3525(25.9)$ \\
\hline
\end{tabular}

$A C L$ anterior cruciate ligament

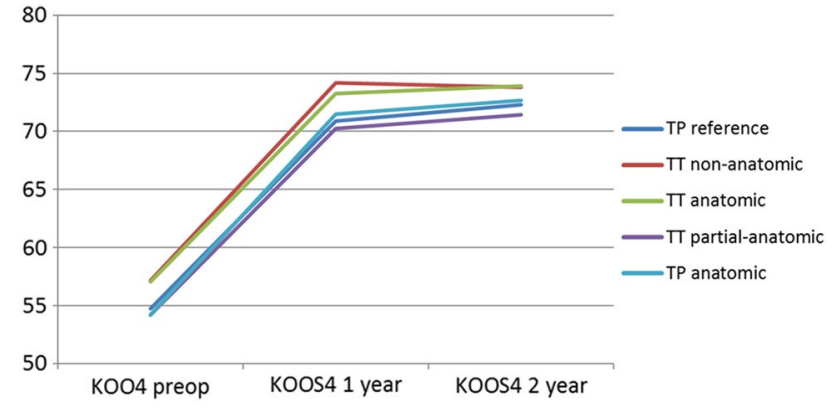

Fig. 2 Average Knee injury and Osteoarthritis Outcome $\mathrm{Score}_{4}$ stratified by surgical technique pre-operatively and at 1- and 2-year follow-up after ACL reconstruction

all surgical techniques of single-bundle ACL reconstruction $(p<0.001)$. No difference in $\mathrm{KOOS}_{4}$ was found between 1- and 2-year follow-up (Table 6).

\section{Discussion}

The main finding of this cohort study on patients after primary ACL reconstruction over a 10 -year period was that surgical techniques of single-bundle reconstruction did not show differences in the change in $\mathrm{KOOS}_{4}$ during the first 2 years after surgery. Thus, the hypothesis was confirmed. However, subjective knee function as measured with $\mathrm{KOOS}_{4}$ improved for all surgical techniques from preoperative to 2-year follow-up after ACL reconstruction.

Surgical techniques of single-bundle ACL reconstruction and optimal graft placement have been studied previously. As one example, grafts that are placed non-anatomically are exposed to lower forces $[3,18]$ and may explain reported differences in graft failure rates [7, 27]. Furthermore, the non-anatomic placement of a graft has the potential to result in residual rotational laxity of the knee, thus creating persisting instability [8] and potentially affecting subjective knee function. This cohort study intended to investigate how the technique of single-bundle ACL reconstruction affected subjective knee function one and 2 years after surgery compared to pre-operatively. No difference in improvement via the $\mathrm{KOOS}_{4}$ was found between the surgical techniques of single-bundle ACL reconstruction. Interestingly, patients who underwent ACL reconstruction with transtibial drilling of the femoral tunnel had a tendency towards superior results in the KOOS pre-operatively, as compared to transportal femoral tunnel drilling. Nevertheless, the repeated measures analyses showed that all surgical techniques of single-bundle ACL reconstruction had similar improvement in KOOS and equivalent results at 2 years after ACL reconstruction. Additionally, the post hoc pairwise comparison of all sub-scales of KOOS revealed that only one significant difference in the KOOS sub-scale of sport and recreation remained at 2-year follow-up; TT anatomic had a higher score than TT partial-anatomic 
Table 4 Changes in Knee injury and Osteoarthritis Outcome Score $_{4}$ from pre-operative to 2-year follow-up after ACL reconstruction

\begin{tabular}{|c|c|c|c|c|c|c|c|c|c|}
\hline $\begin{array}{l}\text { Surgical tech- } \\
\text { nique }\end{array}$ & $\mathrm{KOOS}_{4}$ pre-op & $\mathrm{KOOS}_{4} 1$ year & $\begin{array}{l}\mathrm{KOOS}_{4} \\
2 \text { years }\end{array}$ & $\begin{array}{l}\text { Mean improve- } \\
\text { ment pre- } \\
\text { op-1 year }\end{array}$ & $p$ value & $\begin{array}{l}\text { Mean } \\
\text { improve- } \\
\text { ment pre- } \\
\text { op-2 years }\end{array}$ & $p$ value & $\begin{array}{l}\text { Mean } \\
\text { improvement } \\
1 \text { year-2 years }\end{array}$ & $p$ value \\
\hline $\begin{array}{l}\text { TP reference } \\
\quad(N=1097)\end{array}$ & 54.9 & 73.1 & 72.9 & 18.2 & $<0.001$ & 17.9 & $<0.001$ & -0.2 & n.s. \\
\hline $\begin{array}{c}\text { TP anatomic } \\
(N=779)\end{array}$ & 54.4 & 72.6 & 73.0 & 18.2 & $<0.001$ & 18.6 & $<0.001$ & 0.4 & n.s. \\
\hline $\begin{array}{l}\text { TT anatomic } \\
(N=427)\end{array}$ & 56.2 & 74.3 & 73.6 & 18.1 & $<0.001$ & 17.4 & $<0.001$ & -0.7 & n.s \\
\hline $\begin{array}{l}\text { TT partial- } \\
\text { anatomic } \\
(N=322)\end{array}$ & 54.4 & 69.4 & 71.6 & 15.0 & $<0.001$ & 17.2 & $<0.001$ & 2.2 & n.s. \\
\hline $\begin{array}{l}\text { TT non- } \\
\text { anatomic } \\
(N=298)\end{array}$ & 57.1 & 75.0 & 75.5 & 17.9 & $<0.001$ & 18.4 & $<0.001$ & 0.5 & n.s. \\
\hline
\end{tabular}

$A C L$ anterior cruciate ligament, KOOS Knee injury and Osteoarthritis Outcome Score, $T P$ transportal, $T T$ transtibial

Table 5 Linear mixed model on the interaction of $\mathrm{KOOS}_{4}$ and surgical technique of single-bundle ACL reconstruction adjusted for age at index reconstruction, gender, and concomitant injuries

\begin{tabular}{llcll}
\hline Follow-up & $\begin{array}{l}\text { Surgical tech- } \\
\text { nique }^{\mathrm{a}}\end{array}$ & Estimate & $95 \% \mathrm{CI}$ & $P$ value \\
\hline $\begin{array}{l}\text { Pre-operative to } \\
\text { one year }\end{array}$ & TP reference & -0.27 & {$[-1.87 ; 1.33]$} & n.s. \\
& TP anatomic & 0.94 & {$[-0.74 ; 2.63]$} & n.s. \\
& TT anatomic & -0.004 & {$[-1.87 ; 1.87]$} & n.s. \\
& TT partial- & -1.08 & {$[-3.06 ; 0.89]$} & n.s. \\
ane year to two & TP reference & 0.57 & {$[-0.86 ; 2.01]$} & n.s. \\
years & TP anatomic & 0.76 & {$[-0.74 ; 2.27]$} & n.s. \\
& TT anatomic & 0.08 & {$[-1.57 ; 1.74]$} & n.s. \\
& TT partial- & 1.48 & {$[-0.26 ; 3.22]$} & n.s. \\
& anatomic & & & \\
\hline
\end{tabular}

$C I$ confidence interval, $T P$ transportal, $T T$ transtibial

a $\mathrm{TT}$ non-anatomic set as reference
$(4.53, p=0.006)$ (Supplementary file). This difference was, however, not clinically relevant [30].

The results of the study suggest that no clinically relevant differences are seen in subjective knee function with respect to surgical techniques of single-bundle reconstruction up to 2 years after surgery. Patient-reported knee function, such as the KOOS, has been suggested to provide an indirect evaluation of stability of the knee joint [33]. However, it cannot be ruled out that the KOOS is too nonspecific to identify surgery-related differences in the knee joint and may not be an appropriate outcome for the evaluation of surgical techniques of ACL reconstruction. In comparison, an objective measure of knee stability, such as a quantifiable pivot shift test, can identify small differences in knee joint kinematics and may therefore be better suited as an outcome measurement in this scenario. However, no data on objective measures of knee stability are kept at

Table 6 Improvement in Knee injury and Osteoarthritis Outcome Score $_{4}$ adjusted for age, sex, and concomitant injuries

\begin{tabular}{|c|c|c|c|c|c|c|c|c|c|}
\hline $\begin{array}{l}\text { Surgical tech- } \\
\text { nique }\end{array}$ & $\begin{array}{l}\mathrm{KOOS}_{4} \text { pre-op } \\
(N=9409)\end{array}$ & $\begin{array}{l}\mathrm{KOOS}_{4} 1 \text { year } \\
(N=7271)\end{array}$ & $\begin{array}{l}\mathrm{KOOS}_{4} \\
2 \text { years } \\
(N=6134)\end{array}$ & $\begin{array}{l}\text { Mean improve- } \\
\text { ment pre- } \\
\text { op-1 year }\end{array}$ & $p$ value & $\begin{array}{l}\text { Mean } \\
\text { improve- } \\
\text { ment pre- } \\
\text { op-2 years }\end{array}$ & $p$ value & $\begin{array}{l}\text { Mean } \\
\text { improvement } \\
1-2 \text { years }\end{array}$ & $p$ value \\
\hline TP reference & 53.6 & 70.1 & 70.8 & 16.5 & $<0.001$ & 17.2 & $<0.001$ & 0.7 & n.s. \\
\hline $\mathrm{TP}$ anatomic & 52.9 & 70.6 & 71.5 & 17.7 & $<0.001$ & 18.6 & $<0.001$ & 0.9 & n.s. \\
\hline TT anatomic & 55.7 & 72.5 & 72.6 & 16.8 & $<0.001$ & 16.9 & $<0.001$ & 0.1 & n.s \\
\hline $\begin{array}{r}\text { TT partial- } \\
\text { anatomic }\end{array}$ & 53.1 & 68.8 & 70.4 & 15.7 & $<0.001$ & 17.3 & $<0.001$ & 1.6 & n.s. \\
\hline $\begin{array}{l}\text { TT non-ana- } \\
\text { tomic }\end{array}$ & 55.9 & 72.7 & 72.8 & 16.8 & $<0.001$ & 16.9 & $<0.001$ & 0.1 & n.s. \\
\hline
\end{tabular}

$A C L$ anterior cruciate ligament, KOOS Knee injury and Osteoarthritis Outcome Score, $T P$ transportal, $T T$ transtibial 
follow-up in the SNKLR. Also of interest, the indication of the performed surgical technique and the potential learning curve after a particular technique is used for a period of time was not studied. Intuitively, it can be argued that if patients do not perceive a residual instability of the knee joint, this will limit the negative effect on subjective knee function [7, 8]. In addition, treatment failure in the form of early graft rupture was excluded in the study and may potentially have skewed the results of surgical techniques.

The general linear model created for the repeated measures analysis only included patients with complete $\mathrm{KOOS}_{4}$ data from all three time points of follow-up. The SNKLR has an insufficient response rate of $50-70 \%$ for the patient-reported outcome measures [10]. This led to a large number of patients being excluded from the initial analysis, potentially inflicting bias. A non-response analysis of the SNKLR has been conducted and reported that the SNKLR is valid despite the sub-optimal number of patients responding at follow-up [29]. Nevertheless, to increase the number of patients included in the data analyses, an additional repeated measures analysis was conducted based on a linear mixed model. The linear mixed model allows occasional loss of data unlike the general linear model, which means that the cohort is considerably larger and that estimates are more precise. Interestingly, no differences in the change in $\mathrm{KOOS}_{4}$ from baseline were found with any of repeated measure analyses.

In this study, a retrospective analysis was performed through a web-based questionnaire on surgical data, which, in turn, can entail an element of a recall bias. To minimize recall bias, responders were instructed to only answer the question if they were sure of the date (by specifying the year) that they adopted or abandoned the surgical technique in question. Moreover, all patients that were operated on during the time periods that the surgeon was 'in-between' surgical techniques were not included [7]. Further limitations in this study were that patient-specific data on activity level and rehabilitation were not reported in the registry. For example, objective measures of knee function, such as muscle strength, have been reported to explain a moderate proportion of the variation in patient-reported outcomes after ACL reconstruction [16]. Accordingly, an increased risk of graft failure has been reported when patients do not pass pre-defined goals in functional tests for return to activity and a decision to return to knee strenuous activity $[15,21]$. On average, our results are in line with subjective knee function as measured with the KOOS and reported in the SNKLR [1, 13]. Nevertheless, the results are below the results that have been suggested as a functional recovery among patients after ACL reconstruction [5, 17]. Despite the exclusion of early graft failures, the proportion of patients not achieving an acceptable level of symptoms after treatment is not known in the cohort.
The strength of the present study is that it utilizes a large national registry, which is a unique source of information that consists of data from thousands of patients with a high follow-up rate from both patients and surgeons alike. In addition, to our knowledge, this is one of few studies that include detailed data of surgical technique to investigate patient-reported outcome after ACL reconstruction. Future research should aim to account for the potential confounding factors by including interdisciplinary data, e.g. from orthopaedic surgeons and physical therapists.

\section{Conclusion}

In this study encompassing 13,636 patients from the SNKLR, the surgical technique of primary single-bundle ACL reconstruction did not demonstrate differences in improvement in baseline subjective knee function as measured with the $\mathrm{KOOS}_{4}$ at 2-year follow-up. However, subjective knee function improved from pre-operative baseline to 2-year follow-up independently of surgical technique, with the largest improvement seen in the first year after surgery.

\section{Compliance with ethical standards}

Conflict of interest Each author certifies that he or she has no commercial associations (e.g. consultancies, stock ownership, equity interest, and patent/licensing arrangements) that might pose a conflict of interest in connection with the submitted article.

Funding No fundings were received for this study.

Ethical approval The Regional Ethical Review Board in Gothenburg, Sweden, approved this study (D-nr: 760-14).

Informed consent No written consent is necessary for national registries in Sweden.

Open Access This article is distributed under the terms of the Creative Commons Attribution 4.0 International License (http://creativecommons.org/licenses/by/4.0/), which permits unrestricted use, distribution, and reproduction in any medium, provided you give appropriate credit to the original author(s) and the source, provide a link to the Creative Commons license, and indicate if changes were made.

\section{References}

1. Ahlden M, Samuelsson K, Sernert N, Forssblad M, Karlsson J, Kartus J (2012) The Swedish National Anterior Cruciate Ligament Register: a report on baseline variables and outcomes of surgery for almost 18,000 patients. Am J Sports Med 40(10):2230-2235 
2. Alviar MJ, Olver J, Brand C, Hale T, Khan F (2011) Do patientreported outcome measures used in assessing outcomes in rehabilitation after hip and knee arthroplasty capture issues relevant to patients? Results of a systematic review and ICF linking process. J Rehabil Med 43(5):374-381

3. Araujo PH, Asai S, Pinto M, Protta T, Middleton K, Linde-Rosen M, Irrgang J, Smolinski P, Fu FH (2015) ACL graft position affects in situ graft force following ACL reconstruction. J Bone Joint Surg Am 97(21):1767-1773

4. Ardern CL, Taylor NF, Feller JA, Webster KE (2014) Fifty-five per cent return to competitive sport following anterior cruciate ligament reconstruction surgery: an updated systematic review and meta-analysis including aspects of physical functioning and contextual factors. Br J Sports Med 48(21):1543-1552

5. Barenius B, Forssblad M, Engstrom B, Eriksson K (2013) Functional recovery after anterior cruciate ligament reconstruction, a study of health-related quality of life based on the Swedish National Knee Ligament Register. Knee Surg Sports Traumatol Arthrosc 21(4):914-927

6. Desai N, Alentorn-Geli E, van Eck CF, Musahl V, Fu FH, Karlsson J, Samuelsson K (2016) A systematic review of single- versus double-bundle ACL reconstruction using the anatomic anterior cruciate ligament reconstruction scoring checklist. Knee Surg Sports Traumatol Arthrosc 24(3):862-872

7. Desai N, Andernord D, Sundemo D, Alentorn-Geli E, Musahl V, Fu F, Forssblad M, Samuelsson K (2016) Revision surgery in anterior cruciate ligament reconstruction: a cohort study of 17,682 patients from the Swedish National Knee Ligament Register. DOI, Knee Surg Sports Traumatol Arthrosc. doi:10.1007/ s00167-016-4399-0

8. Driscoll MD, Isabell GP Jr, Conditt MA, Ismaily SK, Jupiter DC, Noble PC, Lowe WR (2012) Comparison of 2 femoral tunnel locations in anatomic single-bundle anterior cruciate ligament reconstruction: a biomechanical study. Arthroscopy 28(10):1481-1489

9. Dunn WR, Wolf BR, Harrell FE Jr, Reinke EK, Huston LJ, Spindler KP (2015) Baseline predictors of health-related quality of life after anterior cruciate ligament reconstruction: a longitudinal analysis of a multicenter cohort at two and six years. J Bone Joint Surg Am 97(7):551-557

10. Emilsson L, Lindahl B, Koster M, Lambe M, Ludvigsson JF (2015) Review of 103 Swedish Healthcare Quality Registries. J Intern Med 277(1):94-136

11. Filbay SR, Ackerman IN, Russell TG, Macri EM, Crossley KM (2014) Health-related quality of life after anterior cruciate ligament reconstruction: a systematic review. Am J Sports Med 42(5):1247-1255

12. Frobell RB, Roos EM, Roos HP, Ranstam J, Lohmander LS (2010) A randomized trial of treatment for acute anterior cruciate ligament tears. N Engl J Med 363(4):331-342

13. Granan LP, Forssblad M, Lind M, Engebretsen L (2009) The Scandinavian ACL registries 2004-2007: baseline epidemiology. Acta Orthop 80(5):563-567

14. Grindem H, Eitzen I, Moksnes H, Snyder-Mackler L, Risberg MA (2012) A pair-matched comparison of return to pivoting sports at 1 year in anterior cruciate ligament-injured patients after a nonoperative versus an operative treatment course. Am J Sports Med 40(11):2509-2516

15. Grindem H, Snyder-Mackler L, Moksnes H, Engebretsen L, Risberg MA (2016) Simple decision rules can reduce reinjury risk by $84 \%$ after ACL reconstruction: the Delaware-Oslo ACL cohort study. Br J Sports Med 50(13):804-808. doi:10.1136/ bjsports-2016-096031

16. Holsgaard-Larsen A, Jensen C, Aagaard P (2014) Subjective vs objective predictors of functional knee joint performance in anterior cruciate ligament-reconstructed patients-do we need both? Knee 21(6):1139-1144

17. Ingelsrud LH, Granan LP, Terwee CB, Engebretsen L, Roos EM (2015) Proportion of patients reporting acceptable symptoms or treatment failure and their associated KOOS values at 6 to 24 months after anterior cruciate ligament reconstruction: a study from the Norwegian Knee Ligament Registry. Am J Sports Med 43(8): 1902-1907

18. Kato Y, Maeyama A, Lertwanich $\mathrm{P}$, Wang JH, Ingham SJ, Kramer S, Martins CQ, Smolinski P, Fu FH (2013) Biomechanical comparison of different graft positions for single-bundle anterior cruciate ligament reconstruction. Knee Surg Sports Traumatol Arthrosc 21(4):816-823

19. King MT (2011) A point of minimal important difference (MID): a critique of terminology and methods. Expert Rev Pharmacoecon Outcomes Res 11(2):171-184

20. Kopf S, Forsythe B, Wong AK, Tashman S, Anderst W, Irrgang JJ, Fu FH (2010) Nonanatomic tunnel position in traditional transtibial single-bundle anterior cruciate ligament reconstruction evaluated by three-dimensional computed tomography. J Bone Joint Surg Am 92(6):1427-1431

21. Kyritsis P, Bahr R, Landreau P, Miladi R, Witvrouw E (2016) Likelihood of ACL graft rupture: not meeting six clinical discharge criteria before return to sport is associated with a four times greater risk of rupture. Br J Sports Med 50(15):946-951

22. Logerstedt D, Grindem H, Lynch A, Eitzen I, Engebretsen L, Risberg MA, Axe MJ, Snyder-Mackler L (2012) Single-legged hop tests as predictors of self-reported knee function after anterior cruciate ligament reconstruction: the Delaware-Oslo ACL cohort study. Am J Sports Med 40(10):2348-2356

23. Lubowitz JH (2014) Anatomic ACL reconstruction produces greater graft length change during knee range-of-motion than transtibial technique. Knee Surg Sports Traumatol Arthrosc 22(5):1190-1195

24. Mannion AF, Junge A, Elfering A, Dvorak J, Porchet F, Grob D (2009) Great expectations: really the novel predictor of outcome after spinal surgery? Spine (Phila Pa 1976) 34(15):1590-1599

25. Palmieri-Smith RM, Lepley LK (2015) Quadriceps strength asymmetry after anterior cruciate ligament reconstruction alters knee joint biomechanics and functional performance at time of return to activity. Am J Sports Med 43(7):1662-1669

26. Rabin R, de Charro F (2001) EQ-5D: a measure of health status from the EuroQol Group. Ann Med 33(5):337-343

27. Rahr-Wagner L, Thillemann TM, Pedersen AB, Lind M (2014) Comparison of hamstring tendon and patellar tendon grafts in anterior cruciate ligament reconstruction in a nationwide population-based cohort study: results from the Danish registry of knee ligament reconstruction. Am J Sports Med 42(2):278-284

28. Rahr-Wagner L, Thillemann TM, Pedersen AB, Lind MC (2013) Increased risk of revision after anteromedial compared with transtibial drilling of the femoral tunnel during primary anterior cruciate ligament reconstruction: results from the Danish Knee Ligament Reconstruction Register. Arthroscopy 29(1):98-105

29. Reinholdsson J, Kraus-Schmitz J, Forssblad M, Edman G, Byttner M, Stalman A (2016) A non-response analysis of 2-year data in the Swedish Knee Ligament Register. Knee Surg Sports Traumatol Arthrosc. doi:10.1007/s00167-015-3969-x

30. Roos EM, Lohmander LS (2003) The knee injury and osteoarthritis outcome score (KOOS): from joint injury to osteoarthritis. Health Qual Life Outcomes 1:64. doi:10.1186/1477-7525-1-64

31. Roos EM, Roos HP, Lohmander LS, Ekdahl C, Beynnon BD (1998) Knee Injury and Osteoarthritis Outcome Score (KOOS) development of a self-administered outcome measure. J Orthop Sports Phys Ther 28(2):88-96

32. Speight J, Barendse SM (2010) FDA guidance on patient reported outcomes. BMJ 340:c2921 
33. Thorstensson CA, Lohmander LS, Frobell RB, Roos EM, Gooberman-Hill R (2009) Choosing surgery: patients' preferences within a trial of treatments for anterior cruciate ligament injury. A qualitative study. BMC Musculoskelet Disord 10:100

34. Xu Y, Ao YF, Wang JQ, Cui GQ (2014) Prospective randomized comparison of anatomic single- and double-bundle anterior cruciate ligament reconstruction. Knee Surg Sports Traumatol Arthrosc 22(2):308-316

35. Xu Y, Liu J, Kramer S, Martins C, Kato Y, Linde-Rosen M, Smolinski P, Fu FH (2011) Comparison of in situ forces and knee kinematics in anteromedial and high anteromedial bundle augmentation for partially ruptured anterior cruciate ligament. Am J Sports Med 39(2):272-278

36. Yamamoto Y, Hsu WH, Woo SL, Van Scyoc AH, Takakura Y, Debski RE (2004) Knee stability and graft function after anterior cruciate ligament reconstruction: a comparison of a lateral and an anatomical femoral tunnel placement. Am J Sports Med 32(8):1825-1832 